\title{
The influence of CONSORT on the quality of reporting of randomised controlled trials: an updated review
}

\author{
Lucy Turner ${ }^{1}$, David Moher ${ }^{1}$, Larissa Shamseer ${ }^{1}$, Laura Weeks ${ }^{1}$, Jodi Peters ${ }^{1}$, Amy Plint $^{2}$, Douglas G Altman ${ }^{3 *}$, \\ Kenneth F Schulz ${ }^{4}$
}

From Clinical Trials Methodology Conference 2011

Bristol, UK. 4-5 October 2011

\section{Background}

The Consolidated Standards of Reporting Trials (CONSORT) Statement was developed in response to concerns about the quality of reporting of randomized controlled trials (RCTs). The checklist is an evidencebased minimum set of recommendations for reporting RCTs, intended to facilitate the complete and transparent reporting of RCTs and aid in their critical appraisal and interpretation. In 2006, Plint and colleagues published a systematic review examining the effectiveness of CONSORT for improving the reporting of RCTs in journals that have formally endorsed the guidance (i.e. at minimum recommend that authors use CONSORT) [1]. Despite poor methodology of some included studies, use of CONSORT was found to be associated with improvement in the quality of reporting of RCTs.

\section{Objective}

To update Plint et al.'s systematic review assessing the influence of the CONSORT Statement's checklist (2001) on the quality of reporting of RCTs.

\section{Methods}

Conventional systematic review methods employed in the original review by Plint et al. have been implemented. The search for new studies spanned August 2005 March 2010. Two independent reviewers screened studies for eligibility; extraction and validity assessment of studies were conducted by a single reviewer and a second reviewer performed verification. Reporting quality was assessed by comparing the proportion of RCTs

${ }^{3}$ Centre for Statistics in Medicine, University of Oxford, Oxford, UK Full list of author information is available at the end of the article adhering to individual CONSORT items or a total sum score between comparison groups.

\section{Results}

Of 2896 possibly relevant studies, 53 reports of 50 quasi-experimental studies have been included, compared to 8 in the earlier review. In total these studies assessed adherence to CONSORT in 16,222 RCTs. When comparing reporting in RCTs of CONSORT endorsing journals with CONSORT non-endorsing journals; 25 of 27 outcomes yield higher relative reporting of these items in endorsing journals, of which 7 were statistically significant. The largest positive effect, across 16 studies, showed that reporting of allocation concealment was $81 \%$ greater in CONSORT endorsing journals $(\mathrm{RR}=1.81,95 \% \mathrm{CI} 1.37$ to 2.40$)$. There is no evidence to suggest that CONSORT endorsement has a detrimental influence on the quality of reporting of RCTs.

\section{Impact}

Despite the questionable validity of the included studies, this updated review provides stronger evidence suggesting that CONSORT is associated with improved reporting of RCTs. This information is helpful to authors, peer-reviewers and journal editors when deciding whether to recommend or enforce the use of CONSORT.

\section{Author details}

1 Ottawa Hospital Research Institute, Ottawa, Canada. ${ }^{2}$ Children's Hospital of Eastern Ontario, Ottawa, Canada. ${ }^{3}$ Centre for Statistics in Medicine, University of Oxford, Oxford, UK. ${ }^{4}$ FHI360, North Carolina, USA.

Published: 13 December 2011 


\section{Reference}

1. Plint AC, Moher D, Morrison A, Altman DG, Schulz K, Hill C, Gaboury I: Does the CONSORT checklist improve the quality of reports of randomised controlled trials? A systematic review. Med J Aust 2006, 185:263-267.

doi:10.1186/1745-6215-12-S1-A47

Cite this article as: Turner et al:: The influence of CONSORT on the quality of reporting of randomised controlled trials: an updated review. Trials 2011 12(Suppl 1):A47.

Submit your next manuscript to BioMed Central and take full advantage of:

- Convenient online submission

- Thorough peer review

- No space constraints or color figure charges

- Immediate publication on acceptance

- Inclusion in PubMed, CAS, Scopus and Google Scholar

- Research which is freely available for redistribution

Submit your manuscript at www.biomedcentral.com/submit 